\title{
RESEARCH
}

Open Access

\section{Diffusion-weighted magnetic resonance imaging (DWMRI) of head and neck squamous cell carcinoma: could it be an imaging biomarker for prediction of response to chemoradiation therapy}

\author{
Hanan Mohamed Khattab ${ }^{1 *}$ (D), Moataz Mohamed Montasser ${ }^{1}$, Mohamed Eid ${ }^{1}$, Alaa Kandil ${ }^{2}$ and
} Salah El-Din Desouky ${ }^{1}$

\begin{abstract}
Background: Chemoradiation therapy (CRT) has become a primary definitive treatment modality for head and neck squamous cell carcinoma (HNSCC); however, not all patients respond completely to treatment. Ability to identify those patients, who would not achieve complete response, before or early during the course of CRT will allow treatment modifications to improve outcome and overall survival. The aim of this prospective study was to assess the usefulness of diffusion-weighted imaging (DWI) in prediction of early therapeutic response of HNSCC after CRT.

Results: Local control was achieved in 22 patients out of 46 patients with pathologically proven HNSCC treated by chemoradiation therapy and local failure was detected in 24 patients out of 46 patients. Pretreatment mean apparent diffusion coefficient ( $A D C_{\text {pre }}$ ) was significantly higher in local failure group $\left(1.1 \pm 0.2 \times 10^{-3} \mathrm{~mm}^{2} / \mathrm{s}\right)$ than local control group $\left(0.89 \pm 0.1 \times 10^{-3} \mathrm{~mm}^{2} / \mathrm{s}\right)$. An optimal cut-off value of more than $0.94 \times 10^{-3} \mathrm{~mm}^{2} / \mathrm{s}$ was predictive of local failure with sensitivity $83.33 \%$, specificity 59.9\%, PPV 69\%, NPV 76.5\%. Early intra-treatment percentage change of ADC $(\triangle A D C)$ was significantly lower in local failure group $(21.8 \% \pm 21.3)$ than in local control group $(45.2 \% \pm 27.8)$. An optimal cut-off value of $\leq 33 \%$ was predictive of local failure after CRT with sensitivity of $71.34 \%$, specificity of $60 \%$, PPV of $62.5 \%$, and NPV of $69.2 \%$.

Conclusions: Diffusion-weighted MRI could be a potential predictive biomarker for therapeutic response of HNSCC to CRT. Primary tumors with higher pretreatment mean ADC, and a smaller early intratreatment percentage increase of mean ADC would be more likely to fail treatment.
\end{abstract}

Keywords: Head and neck squamous cell carcinoma, Diffusion-weighted MRI, Chemoradiation therapy

\footnotetext{
* Correspondence: drhanankhattab85@gmail.com

'Department of Diagnostic and Interventional Radiology, Faculty of

Medicine, Alexandria University, Alexandria, Egypt

Full list of author information is available at the end of the article
}

\section{Springer Open}

(๑) The Author(s). 2020 Open Access This article is licensed under a Creative Commons Attribution 4.0 International License, which permits use, sharing, adaptation, distribution and reproduction in any medium or format, as long as you give appropriate credit to the original author(s) and the source, provide a link to the Creative Commons licence, and indicate if changes were made. The images or other third party material in this article are included in the article's Creative Commons licence, unless indicated otherwise in a credit line to the material. If material is not included in the article's Creative Commons licence and your intended use is not permitted by statutory regulation or exceeds the permitted use, you will need to obtain permission directly from the copyright holder. To view a copy of this licence, visit http://creativecommons.org/licenses/by/4.0/. 


\section{Background}

Squamous cell carcinoma accounts for $95 \%$ of all head and neck cancers. The choice of treatment modality depends on how to provide cure with maximum possible preservation of organ function [1].

During recent years, chemoradiation therapy (CRT) has become a primary definitive treatment modality for head and neck cancer, allowing for preservation of organ function (swallowing and speech) with survival rates equal to surgery; however, about $30 \%$ of patients do not respond to CRT leading to locoregional failure [2, 3].

The ability to identify patients who would not respond to CRT allows for modification of treatment strategies such as adding a boost of radiation therapy at the end of initial treatment, additional targeted therapies, or even shifting treatment strategy from CRT to surgery and subsequently improvement of cure and survival rates, also this will avoid the unnecessary toxic side effects of CRT, but this requires early diagnostic biomarkers that can predict later tumor response and identify patients who would benefit from these modifications [4-6].

Predictive imaging biomarkers before or early after initiation of radiation therapy of $\mathrm{HNC}$ are of great interest in recent researches, including PET-CT, perfusion-CT, and functional MRI studies either perfusion or diffusion imaging studies [7-9].

MRI is an attractive tool because it does not involve ionizing radiation, better soft tissue evaluation, and is the imaging method of choice in head and neck squamous cell carcinoma for initial anatomical staging and follow-up [10]. Diffusion-weighted magnetic resonance imaging (DWI) is a quantitative relatively rapid MRI sequence that can be easily incorporated into routine patient examination without need for exogenous contrast agent. It has the ability to act as a potential marker for tissue cellularity which affects tumor response to CRT $[11,12]$.

DWI is a noninvasive imaging technique that measures the relative mobility of water molecules in different tissue microstructures which depends on cell size, density, integrity of cellular membrane and tissue vascularity. In the diffusion sequence, two large gradient pulses are used, equal in strength (which is determined by the $b$ value) but in opposite directions. The first gradient pulse induces a phase shift of water molecules, and the second pulse for rephrasing; however, the moving water molecules will lead to incomplete rephrasing and signal loss $[11,13]$. The amount of signal loss on diffusion images with increasing $b$ values can be quantified using the apparent diffusion coefficient (ADC) which shows an inverse correlation with tissue cellularity. Hypercellular tumors are associated with less signal loss and low ADC values while hypocellular tumors or tumors containing multiple necrotic foci are associated with more signal loss and high $\operatorname{ADC}[2,8,14]$. DWI has another great advantage that it is sensitive to microscopic pathologic changes before they became visible on conventional MRI sequences $[8,15]$.

The aim of this prospective study was to evaluate the potential usefulness of pretreatment and early intratreatment DWI in prediction of therapeutic response of HNSCC to CRT.

\section{Methods}

The local ethics committee approved the study protocol and written informed consent was obtained from all participants. Seventy-four patients with pathologically proven, previously untreated head and neck squamous cell carcinoma, planned to be treated with CRT, presented to the Outpatient Clinic of the Clinical Oncology Department from March 2017 to October 2019 and referred to the Radiodiagnosis Department for imaging were enrolled in the study. Twenty-eight patients were excluded due to starting induction chemotherapy before MRI $(n=7)$, change of management plan from CRT to surgery or palliative treatment $(n=4)$, technical difficulties leading to diffusion image distortion $(n=3)$, patient's death due to unrelated causes and final response status could not be determined $(n=4)$, claustrophobia ( $n$ $=3)$, withdrawal from the study $(n=1)$, and too small lesions to be detected on MRI $(n=6)$. Eventually, 46 patients were eligible for the study. Patient's characteristics are demonstrated at Table 1. All tumors were staged according to the American Joint Committee on cancer TNM staging system, 8th edition, 2017.

All patients were subjected to complete history taking, clinical and endoscopic assessment as well as histopathological diagnosis of SCC. Pretreatment diagnostic studies were done including contrast-enhanced CT and MRI examinations with diffusion-weighted imaging.

All patients had been treated with 3D conformal radiation therapy (The radiation therapy regimen included a total fractionated dosage of 70 Gy that was given in 35 daily fractions at a daily dose of 200 cGy per fraction.). Thirty-nine patients had received concurrent chemotherapy (cisplatin $40 \mathrm{mg} / \mathrm{m}^{2}$ that was given weekly along with the radiotherapy for 7 weeks) and 7 patients had been treated by radiotherapy alone. Thirty-two patients had received induction chemotherapy prior to definitive chemoradiation therapy; the induction chemotherapy regimen included $3-4$ cycles of cisplatin $\left(25 \mathrm{mg} / \mathrm{m}^{2} /\right.$ day for 3-4 days) and 5-fluorouracil $\left(1000 \mathrm{mg} / \mathrm{m}^{2} /\right.$ day for 4 days), the cycle was repeated every 3 weeks.

MRI was repeated without contrast administration 2-3 weeks after start of CRT in 31 patients, two of them were excluded as the tumor became too small to be measured.

The endpoint of the study was assessment of therapeutic response 4-12 weeks after the end of CRT, (mean = 7 weeks), by clinical, endoscopic assessment, and MRI examination. The response was determined according to RECI ST 1.1 criteria and patients were classified into two groups: 
Table 1 Patients characteristics

\begin{tabular}{|c|c|}
\hline Characteristic & Number (\%) \\
\hline Total number of patients & 46 \\
\hline Age (mean \pm SD) & $50.8 \pm 16.6$ \\
\hline Range & $11-78$ \\
\hline \multicolumn{2}{|l|}{ Gender } \\
\hline - Male & $27(58.7 \%)$ \\
\hline - Female & 19(41.3\%) \\
\hline \multicolumn{2}{|l|}{ Tumor sites } \\
\hline - Larynx & $16(34.8 \%)$ \\
\hline - Nasopharynx & $9(19.6 \%)$ \\
\hline - Oropharynx & $1(2.2 \%)$ \\
\hline • Hypopharynx & $10(21.7 \%)$ \\
\hline - Oral tongue & $5(10.9 \%)$ \\
\hline - Sinonasal & $3(6.5 \%)$ \\
\hline • Palatal & $1(2.2 \%)$ \\
\hline - Upper gingival & $1(2.2 \%)$ \\
\hline \multicolumn{2}{|l|}{ Histologic grade of differentiation } \\
\hline - Well differentiated & $5(10.9 \%)$ \\
\hline - Moderately differentiated & 29 (63\%) \\
\hline - Undifferentiated & $12(26.1 \%)$ \\
\hline \multicolumn{2}{|l|}{ TNM } \\
\hline $\mathrm{T} 1$ & $3(6.5 \%)$ \\
\hline $\mathrm{T} 2$ & $3(6.5 \%)$ \\
\hline T3 & $13(28.3 \%)$ \\
\hline $\mathrm{T} 4 / \mathrm{T} 4 \mathrm{a}$ & $22(47.8 \%)$ \\
\hline T4b & $5(10.9 \%)$ \\
\hline NO & $21(45.7 \%)$ \\
\hline N1 & $5(10.9 \%)$ \\
\hline N2 & $16(34.8 \%)$ \\
\hline N3 & $4(8.7 \%)$ \\
\hline \multicolumn{2}{|l|}{ Stage groups } \\
\hline$\|$ & $2(4.3 \%)$ \\
\hline III & $11(23.9 \%)$ \\
\hline IVA & $23(50 \%)$ \\
\hline IVB & $10(21.7 \%)$ \\
\hline \multicolumn{2}{|l|}{ Treatment } \\
\hline - Concomitant chemoradiation therapy & 39 (84.4\%) \\
\hline - Radiation therapy & $7(15.2 \%)$ \\
\hline \multicolumn{2}{|l|}{ - Neoadjuvant chemotherapy: } \\
\hline o Yes & $32(69.6 \%)$ \\
\hline o No & 14 (30.4\%) \\
\hline
\end{tabular}

- Local control ( $n=22,47.8 \%$ of patients) was determined as complete disappearance of the tumor $(C R)$, that is further confirmed by histopathological examination (in three patients only) (biopsy was done due to presence of suspicious lesions on endoscopic assessment) as well as further follow up by clinical and cross-sectional imaging assessment for a period of 4-19 months (mean $=9.5$ months) that revealed no development of any suspicious lesions as well as stationary or decreasing existing posttherapeutic lesions.

- Local failure (patients who did not achieve complete response) ( $n=24,52.2 \%$ of patients) was determined as presence of persistent or progressive tumor (stable or progressive disease, SD or PD), residual tumor (partial response, $\mathrm{PR}$ ), or death of the patient during or after treatment due to the disease. The presence of residual tumor was confirmed by histopathological examination (in three patients only), PET-CT studies (in another three patients, with findings matching with residual tumor), and/or further follow-up imaging studies that revealed progression in size of the previously detected lesions.

The MR studies were performed on 3-T MR system (Ingenia, Philips, Healthcare, Best, the Netherlands) using 16-channel head-neck surface coil. All sequences extended from the skull base to the thoracic inlet, covering the primary lesion and all nodal stations. The imaging protocol included:

- Conventional sequences including: axial T2mDIXON(TR/TE 2829/79 ms, FOV $230 \times 230 \times 165$, FA 100, slice thickness $3 \mathrm{~mm}$, intersection gap $0.3 \mathrm{~mm}$, reconstruction matrix 480), axial T1-mDIXON (TR/TE $570 / 7.4 \mathrm{~ms}$, FOV $200 \times 200 \times 165$, FA 90, slice thickness $3.5 \mathrm{~mm}$, intersection gap $1 \mathrm{~mm}$, reconstruction matrix 512), coronal T2-mDIXON (TR/ TE $2542 / 80 \mathrm{~ms}$, FOV $200 \times 200 \times 100$, FA 90, slice thickness $3 \mathrm{~mm}$, intersection gap $0.3 \mathrm{~mm}$, reconstruction matrix 512), all are multishot TSE sequences. T1-weighted sequence was repeated after intravenous GAD administration in the axial, coronal, and sagittal planes.

- Diffusion-weighted imaging: in our institution, using single-shot spin-echo echo planar imaging (SS-EPI) in diffusion imaging of the neck on 3-T MR system was associated with significant susceptibility artifacts and geometric distortion, so we preferred to use non-EPI TSE-based DWI that showed much less susceptibility artifacts. It was done in the axial plane (TR/TE 3000/ $72 \mathrm{~ms}$, FOV $230 \times 230 \times 200$, FA 90, slice thickness 3 $\mathrm{mm}$, intersection gap $1 \mathrm{~mm}$, reconstruction matrix 240, parallel imaging SENSE, fat suppression SPIR) with $2 b$ values of 0 and $1000 \mathrm{~mm}^{2} / \mathrm{s}$.

\section{Data analysis}

Analysis of MR examinations was performed manually by two independent radiologists with 25 and 8 years of experience in head and neck radiology. The primary 
tumor was identified on the conventional TSE MR sequences, then visual analysis of the DW images and ADC map was done in conjunction with the coregistered anatomical images (DW images could not be analyzed separately due to their low spatial resolution).

The volume of the primary tumor was measured in axial fat suppressed T2 images or post-GAD fat suppressed T1 weighted images in which the tumor was well delineated, by placing freehand regions of interest (ROIs) around the margins of the tumor in all imaging slices including necrotic or cystic areas and excluding areas filled with air or subjected to image distortion. The tumor volume was measured in the pretreatment $\left(\mathrm{TV}_{\mathrm{pre}}\right)$ as well as midtreatment $\left(\mathrm{TV}_{\text {mid }}\right)$ MRI studies, then the percentage change of tumor volume $(\Delta T V)$ was computed: $\Delta \mathrm{TV}=\left(\mathrm{TV}_{\text {pre }}-\mathrm{TV}_{\text {mid }}\right) / \mathrm{TV}_{\text {pre }} \times 100$

Mean ADC of the whole tumor was measured on the ADC map in the same way by placing freehand regions of interest (ROIs) around the margins of the tumor in all imaging slices including necrotic or cystic areas, then exported as $\mathrm{xml}$ file to be retrieved by SPSS program for histogram analysis and calculation of ADC skewness and kurtosis in the whole tumor that were considered as indicators for tumor heterogeneity. ADC skewness represents the skew of the shape of ADC distribution curve within the tumor, it is positive when the long tail of the curve is to the right and negative when the long tail of the curve if to the left. ADC kurtosis represents the sharpness of the peak of ADC distribution curve, broader peak denoted lower kurtosis, and more heterogenous ADC distribution while sharper peak denotes higher kurtosis and less heterogenous ADC distribution.

On midtreatment studies, mean $\mathrm{ADC}\left(\mathrm{ADC}_{\text {mid }}\right)$ was measured in the same way, then percentage change of ADC $(\triangle \mathrm{ADC})$ was computed: $\triangle \mathrm{ADC}=\left(\mathrm{ADC}_{\text {mid }}-\mathrm{ADC}_{\mathrm{pre}}\right) /$ $\mathrm{ADC}_{\text {pre }} \times 100$

Horos dicom viewer was used for image interpretation, data analysis, and measurements.
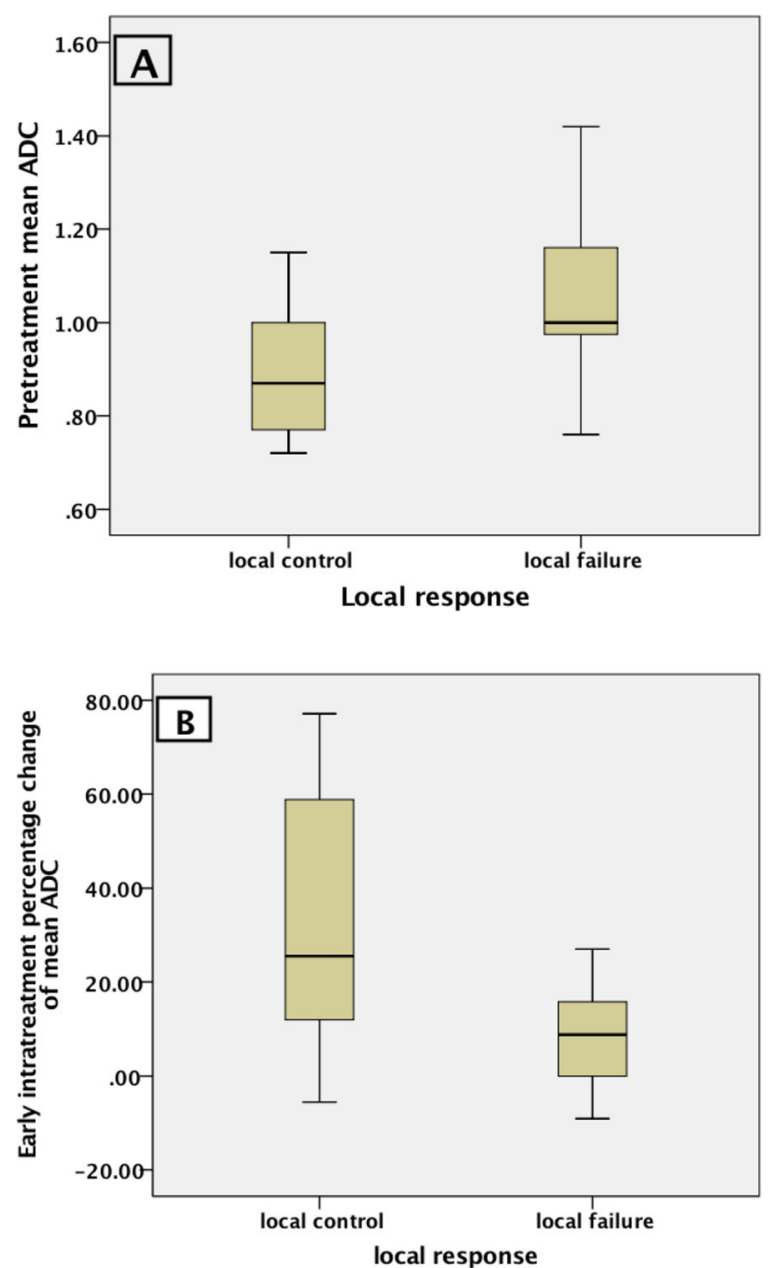

Fig. 1 Box-Whisker plots comparing the pretreatment mean $A D C$ in $\mathbf{a}$ and early intratreatment percentage change of mean $A D C$ in $\mathbf{b}$ between local control and local failure patient groups. Local failure patient group shows significantly higher $A D C_{\text {pre }}$ and lower $\triangle A D C$ 


\section{Statistical analysis}

Kolmogorov-Smirnov tests were used to assess the normality of distribution of our data. Because the MRI data was not normally distributed, Mann-Whitney test was performed to look for differences in primary tumor volume and ADC measurements between local control and local failure groups. $P$ value of $<0.05$ was considered significant. Receiver-operating characteristics (ROC) analysis with the area under the curve (AUC) was employed to assess the discriminatory capability of pretreatment mean $\mathrm{ADC}\left(\mathrm{ADC}_{\mathrm{pre}}\right)$ and early intratreatment percentage change of mean $\mathrm{ADC}(\triangle \mathrm{ADC})$ with calculation of the optimal cut-

Table 2 Comparison of tumor volume and ADC measurements between local control and local failure patient groups

\begin{tabular}{|c|c|c|c|}
\hline & $\begin{array}{l}\text { Local } \\
\text { control }\end{array}$ & Local failure & $P$ \\
\hline Before treatment (total $=46$ ) & $(n=22)$ & $(n=24)$ & \\
\hline \multicolumn{4}{|c|}{ Mean ADC $\left(A D C_{\text {pre }}\right)\left(\times 10^{-3} \mathrm{~mm}^{2} / \mathrm{s}\right)$} \\
\hline Min.-Max. & $0.7-1.2$ & $0.76-1.4$ & $0.001^{*}$ \\
\hline Mean \pm SD & $0.89 \pm 0.1$ & $1.1 \pm 0.2$ & \\
\hline Median (IQR) & $0.87(0.8-1)$ & $1(0.98-1.2)$ & \\
\hline \multicolumn{4}{|l|}{ ADC skewness } \\
\hline Min.-Max. & $-0.55-1.6$ & $-0.69-0.96$ & 0.442 \\
\hline Mean $\pm S D$ & $0.53 \pm 0.67$ & $0.39 \pm 0.45$ & \\
\hline Median (IQR) & $0.53(0.04-1.1)$ & $0.45(0.12-0.79)$ & \\
\hline \multicolumn{4}{|l|}{ ADC kurtosis } \\
\hline Min.-Max. & $-0.68-8.8$ & $0.09-4.1$ & 0.792 \\
\hline Mean \pm SD & $2.4 \pm 2.9$ & $1.4 \pm 0.99$ & \\
\hline Median (IQR) & $1.8(0.15-3.5)$ & $1.3(0.74-2)$ & \\
\hline \multicolumn{4}{|l|}{ Tumor volume $\left(\mathrm{TV}_{\text {pre }}\right)\left(\mathrm{cm}^{3}\right)$} \\
\hline Min.-Max. & $0.5-127.5$ & $1.6-120$ & 0.097 \\
\hline Mean \pm SD & $27.3 \pm 33.6$ & $35.1 \pm 26.4$ & \\
\hline Median (IQR) & $11.3(4-35)$ & $28.4(21.5-43.6)$ & \\
\hline Midtreatment (total $=29$ ) & $(n=15)$ & $(n=14)$ & \\
\hline \multicolumn{4}{|l|}{$\triangle \mathrm{ADC}(\%)$} \\
\hline Min.-Max. & $13.9-118.8$ & $-3.5-66.3$ & $0.008^{*}$ \\
\hline Mean \pm SD & $45.2 \pm 27.8$ & $21.8 \pm 21.3$ & \\
\hline Median (IQR) & $38.9(26.9-52.5)$ & $14.1(9.7-34.1)$ & \\
\hline \multicolumn{4}{|l|}{$\mathrm{TV}_{\text {mid }}\left(\mathrm{cm}^{3}\right)$} \\
\hline Min.-Max. & $0.68-65$ & $3-117$ & $0.007^{*}$ \\
\hline Mean \pm SD & $8.76 \pm 14.4$ & $25.5 \pm 32.8$ & \\
\hline Median (IQR) & $2.5(0.9-7.9)$ & $14.9(3.6-30)$ & \\
\hline \multicolumn{4}{|l|}{$\Delta \mathbf{T V}(\%)$} \\
\hline Min. - Max. & $15.2-95.1$ & $-96.9-89.7$ & 0.100 \\
\hline Mean \pm SD. & $61.6 \pm 28$ & $24 \pm 62.3$ & \\
\hline Median (IQR) & $72.8(32.3-80.9)$ & $36.4(2.3-\backslash 79.3)$ & \\
\hline
\end{tabular}

$P P$ value for comparing between the two groups using Mann-Whitney test

*Statistically significant at $P \leq 0.05$
Table 3 Comparison between mean ADC before and during treatment

\begin{tabular}{llll}
\hline & ADC $_{\text {pre }}$ & ADC $_{\text {mid }}$ & $\boldsymbol{P}$ \\
\hline Total $(\boldsymbol{n}=\mathbf{2 9})$ & & & \\
Min.-Max. & $0.7-1.4$ & $0.9-1.9$ & $<0.001$ \\
Mean $\pm \mathrm{SD}$ & $1 \pm 0.2$ & $1.3 \pm 0.2$ & \\
Median (IQR) & $1.0(0.9-1)$ & $1.3(1.1-1.4)$ & \\
Local control $(\boldsymbol{n}=\mathbf{1 5})$ & & & \\
Min.-Max. & $0.7-1.2$ & $0.9-1.9$ & 0.001 \\
Mean \pm SD & $0.9 \pm 0.1$ & $1.3 \pm 0.3$ & \\
Median (IQR) & $0.9(0.8-1)$ & $1.3(1-1.1)$ & \\
Local failure $(\boldsymbol{n}=\mathbf{1 4})$ & & & \\
Min.-Max. & $0.8-1.4$ & $1-1.6$ & 0.002 \\
Mean \pm SD & $1 \pm 0.2$ & $1.2 \pm 0.2$ & \\
Median (IQR) & $1(1.1-1.4)$ & $1.2(1.1-1.4)$ & \\
\hline PP valu for compaing & &
\end{tabular}

$P P$ value for comparing between pretreatment and midtreatment mean ADC using Wilcoxon signed-ranks test Statistically significant at $p \leq 0.05$

off value, sensitivity, specificity, PPV, and NPV for both. Univariate analysis of other clinical variables that may affect the therapeutic response were done including age, TNM staging classification and histological grade of differentiation using chi-square test. All data analyses were performed using a statistical tool, SPSS (Statistical Package for the Social Sciences, Version 23; IBM, Armonk, NY).

\section{Results}

The distribution of pretreatment mean ADC values $\left(\mathrm{ADC}_{\mathrm{pre}}\right)$ and their midtreatment percentage change $(\triangle \mathrm{ADC})$ among local control and local failure patient groups is demonstrated in the first figure (Fig. 1). Pretreatment mean ADC was significantly higher in local failure than local control patient groups $(P=0.001)$. The pretreatment tumor volume $\left(\mathrm{TV}_{\mathrm{pre}}\right)$ was higher in local failure group than local control group but it was not statistically significant $(P>0.05)$ (Table 2$)$.

The pretreatment mean ADC of the primary tumors $\left(\mathrm{ADC}_{\mathrm{pre}}\right)$ increased significantly $2-3$ weeks after the start of CRT in the whole group of patients $(P<0.001)$ as well as in both local control $(P=0.001)$ and local failure $(P=0.002)$ patient groups (Table 3$)$. Percentage increase in early intratreatment mean ADC $(\triangle \mathrm{ADC})$ was significantly higher in local control than local failure patient groups $(P=0.008)$. The absolute mid treatment tumor volume $\left(\mathrm{TV}_{\text {mid }}\right)$ was significantly higher in local failure patient group $(P=0.007)$, while the percentage change of tumor volume $(\Delta \mathrm{TV})$ was higher in local control group, yet without statistical significance $(P=0.1)$ (Table 2). Univariate analysis for other clinical variables showed no significant difference between both groups $(P>0.05)$. 

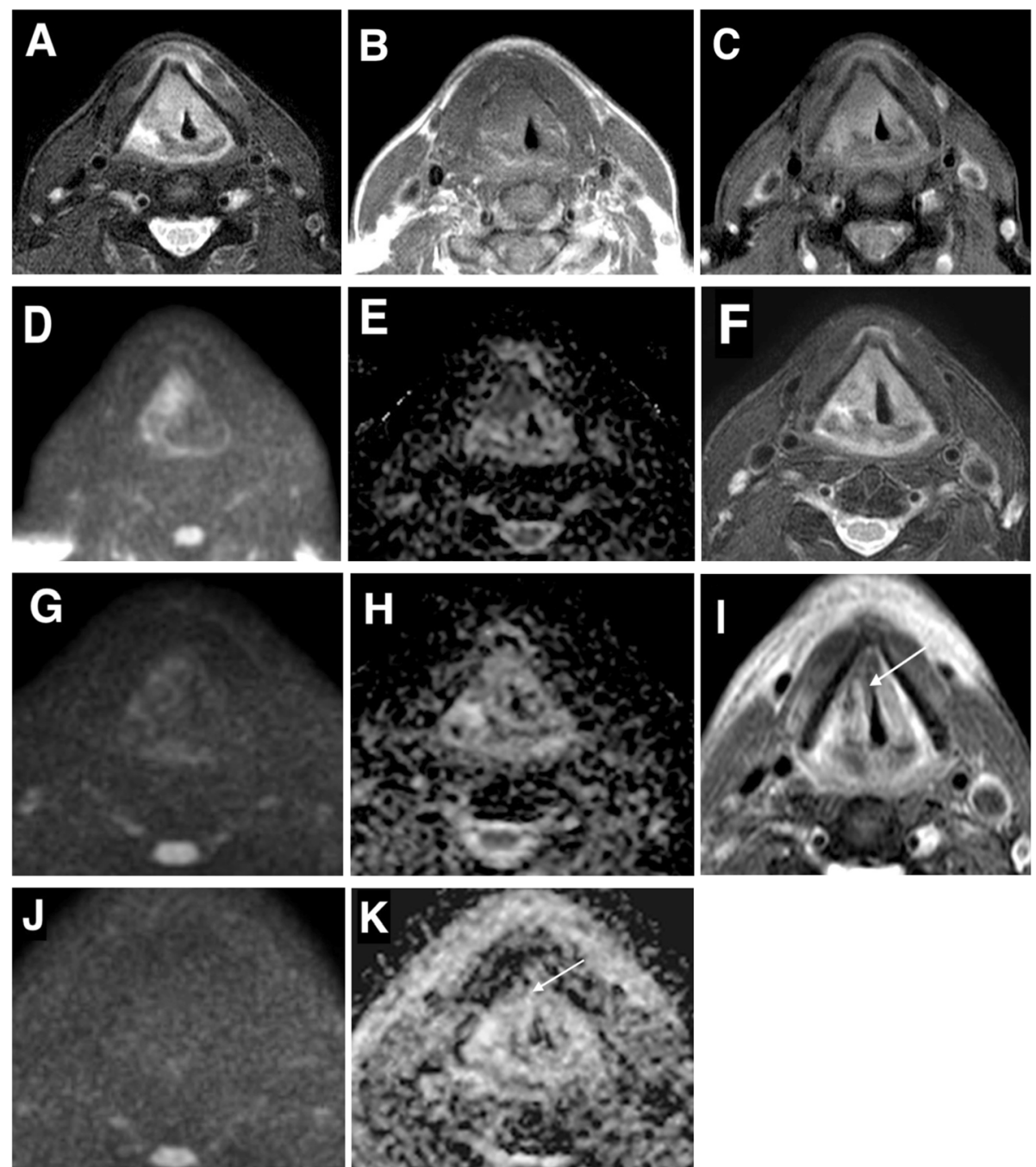

Fig. 2 A 59-year-old male patient with right sided transglottic laryngeal SCC (T4aNOMO) treated by radiotherapy. a-e Axial pretreatment MR images. a T2WI with fat suppression, b non-contrast T1WI, c post-GAD T1WI with fat suppression, $\mathbf{d}$ b-1000 TSE-DWI, e the corresponding ADC map, all showed moderately hyperenhancing T2 hyperintense right sided transglottic soft tissue mass with restricted diffusion $\left(A D C=0.82 \times 10^{-3}\right.$ $\left.\mathrm{mm}^{2} / \mathrm{s}\right), \mathbf{f}-\mathbf{h}$ axial midtreatment MR images performed 2 weeks after start of radiotherapy. $\mathbf{f}$ T2WI with fat suppression. $\mathbf{g}$ b-1000 TSE-DWI, $\mathbf{h}$ the corresponding ADC map, all showed mild regression in size of the tumor with elevation of ADC value $\left(1.26 \times 10^{-3} \mathrm{~mm}^{2} / \mathrm{s}\right)$. i-k Axial MR images 6 weeks after end of radiation therapy. $\mathbf{i}$ T2WI, $\mathbf{j}$ b-1000 TSE-DWI, $\mathbf{k}$ the corresponding ADC map, revealed local control and complete disappearance of the tumor without diffusion restriction. Clinical/radiological follow-up for 1 year after end of treatment showed no development of any new mass or complaint

Two representative cases for local control are demonstrated in the Figs. 2 and 3 showing low $\mathrm{ADC}_{\mathrm{pre}}$ and high $\triangle \mathrm{ADC}$, other two cases of local failure are demonstrated in the Figs. 4 and 5 showing higher $\mathrm{ADC}_{\text {pre }}$ and low $\triangle \mathrm{ADC}$.

On histogram analysis of pretreatment ADC of the whole tumors, no statistically significant difference was found in ADC skewness or kurtosis $(P>0.05)$ between both groups (Table 2), while tumors with local failure were likely to have higher percentage of tumor voxels with high ADC values than tumors with local control as shown in Fig. 6 illustrating histogram of ADC distribution through the primary tumors of the representative cases.

ROC analysis for $\mathrm{ADC}_{\text {pre }}$ determined an optimal cutoff value of $>0.94 \times 10^{-3} \mathrm{~mm}^{2} / \mathrm{s}$ to predict local failure after CRT with sensitivity of $83.33 \%$ specificity of $59.09 \%$, positive predictive value of $69 \%$, and negative predictive value of $76.5 \%$. ROC analysis for $\triangle \mathrm{ADC}$ determined an optimal cut-off value of $\leq 33 \%$ to predict local failure after CRT with sensitivity of $71.34 \%$, specificity of $60 \%$, positive predictive value of $62.5 \%$, and negative predictive value of $69.2 \%$ (Fig. 7) (Table 4). 

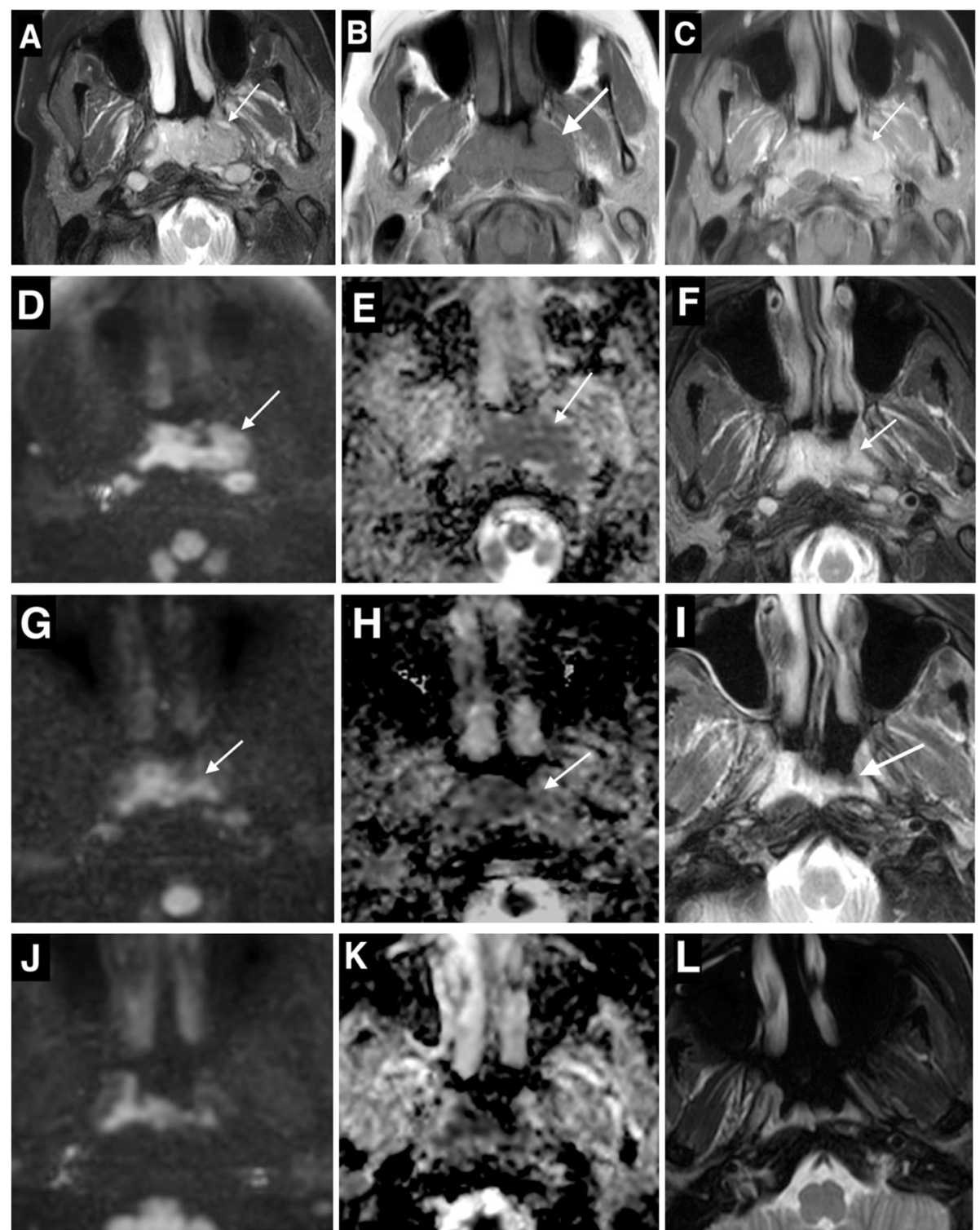

Fig. 3 A 28-years-old female patient with stage III nasopharyngeal SCC (T1N2M0) treated by concomitant chemoradiotherapy. a-e axial pretreatment MR images. a T2WI with fat suppression, $\mathbf{b}$ non-contrast T1WI, $\mathbf{c}$ post-GAD T1WI with fat suppression, $\mathbf{d}$ b-1000 TSE-DWI, e the corresponding ADC map, all showed mainly left-sided nasopharyngeal soft tissue mass with restricted diffusion (ADC $\left.=0.7 \times 10^{-3} \mathrm{~mm}^{2} / \mathrm{s}\right), \mathbf{f}-\mathbf{h}$ axial midtreatment MR images performed 2 weeks after start of chemoradiotherapy. $\mathbf{f}$ T2Wl with fat suppression, $\mathbf{g}$ b-1000 TSE-DWl, $\mathbf{h}$ the corresponding ADC map, all showed mild regression of tumor size with elevation of ADC value $\left(1.3 \times 10^{-3} \mathrm{~mm}^{2} / \mathrm{s}\right)$. i-k Axial MR images 6 weeks after end of CRT, i T2WI with fat suppression, $\mathbf{j}$ b-1000 TSE-DWI, $\mathbf{k}$ the corresponding ADC map, revealed complete disappearance of the tumor leaving thin smooth nasopharyngeal mucosa, yet showing restricted diffusion (ADC $=0.97 \times 10^{-3} \mathrm{~mm}^{2} / \mathrm{s}$ ) so residual tumor was still suspected. I Axial T2WI with fat suppression 1.5 years after end of treatment showed stationary appearance with no development of any new mass confirming local control of the tumor and that it was normal nasopharyngeal lymphoid tissue

\section{Discussion}

This prospective study assessed the correlation between ADC measurements of primary HNSCC before and early during the course of CRT and therapeutic response after completion of treatment. Patients were classified according to their response to treatment into two groups, local control group (who achieved complete response after CRT), and local failure group (in whom residual tumor was detected or the patients had died due to the disease during or after treatment).

Pretreatment mean ADC was significantly higher in local failure group $\left(1.1 \pm 0.2 \times 10^{-3} \mathrm{~mm}^{2} / \mathrm{s}\right)$ than local control group $\left(0.89 \pm 0.1 \times 10^{-3} \mathrm{~mm}^{2} / \mathrm{s}\right)$. An optimal cut-off value of more than $0.94 \times 10^{-3} \mathrm{~mm}^{2} / \mathrm{s}$ was predictive of local failure. High ADC value of the tumor reflects its low cellularity, high stromal content, 

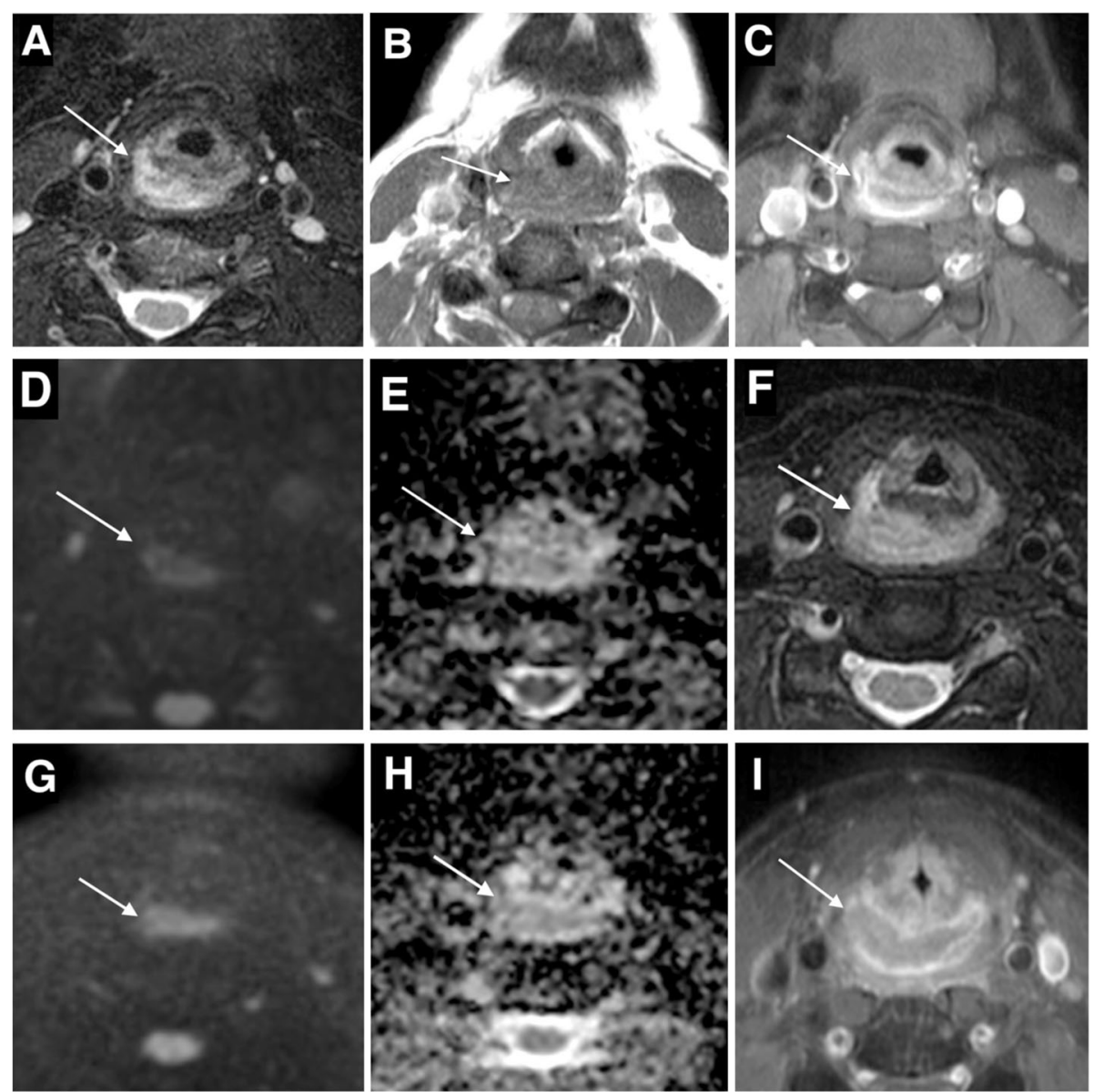

Fig. 4 A 39-year-old female patient with stage III hypopharyngeal SCC (T2N1M0) treated by concomitant chemoradiotherapy. a-e Axial pretreatment MR images. a T2WI with fat suppression, $\mathbf{b}$ non-contrast T1WI, c post-GAD T1WI with fat suppression, $\mathbf{d}$ b-1000 TSE-DWI, e the corresponding ADC map, all showed moderately hyperenhancing T2 hyperintense hypopharyngeal soft tissue mass involving the right pyriform sinus and postcricoid region, DWI shows high ADC $\left(1.42 \times 10^{-3} \mathrm{~mm}^{2} / \mathrm{s}\right)$. $\mathbf{f}-\mathbf{h}$ Axial midtreatment MR images performed 3 weeks after start of chemoradiotherapy. $\mathbf{f}$ T2WI with fat suppression, $\mathbf{g}$ b-1000 TSE-DWI, $\mathbf{h}$ the corresponding ADC map, all showed mild progression in size of the tumor with no elevation of $A D C$ value $\left(A D C=1.37 \times 10^{-3} \mathrm{~mm}^{2} / \mathrm{s}\right)$. $\mathbf{i}$ Axial post-GAD T1WI with fat suppression 8 weeks after end of CRT revealed no response to treatment with progressive tumor that was proved by endoscopic assessment and biopsy

micronecrosis, and mostly negative HPV status, all contributes to tumor resistance to CRT and treatment failure $[16,17]$.

Mean ADC increased significantly 2-3 weeks after start of CRT in both local failure and local control patient groups, this was attributed to cellular death and damage of cell membrane barriers which facilitates diffusion of water molecules [18-20]. Significant smaller percentage increase of mean ADC was found in local failure group $(21.8 \% \pm 21.3)$ than in local control group $(45.2 \% \pm 27.8)$. A threshold of less than $33 \%$ increase of mean ADC was significant predictor of local failure.

These results were in agreement with other two studies, one study assessed the role of DWI in monitoring therapy in HNSCC and found that pretreatment ADC was significantly lower in complete responders with cutoff value of $\leq 0.98 \times 10^{-3} \mathrm{~mm}^{2} / \mathrm{s}$ was identified as significant predictor of local control [21]. The second study was performed on metastatic HNSCC nodes; they found that complete responders had lower pretreatment ADC $\left(1.04 \pm 0.19 \times 10^{-3} \mathrm{~mm}^{2} / \mathrm{s}\right)$ than partial/non-responders $\left(1.35 \pm 0.3 \times 10^{-3} \mathrm{~mm}^{2} / \mathrm{s}\right)$ and identified optimal cut-off value of $1.11 \times 10^{-3} \mathrm{~mm}^{2} / \mathrm{s}$ for differentiating complete and partial responders [22].

Other studies assessing the efficacy of pretreatment ADC measurements in predicting therapeutic response found that complete responders exhibited lower pretreatment $\mathrm{ADC}$ than non-responders but they were not statistically significant $[3,5,6,15]$.

Other several studies were also compatible with this study as regards the early intratreatment 

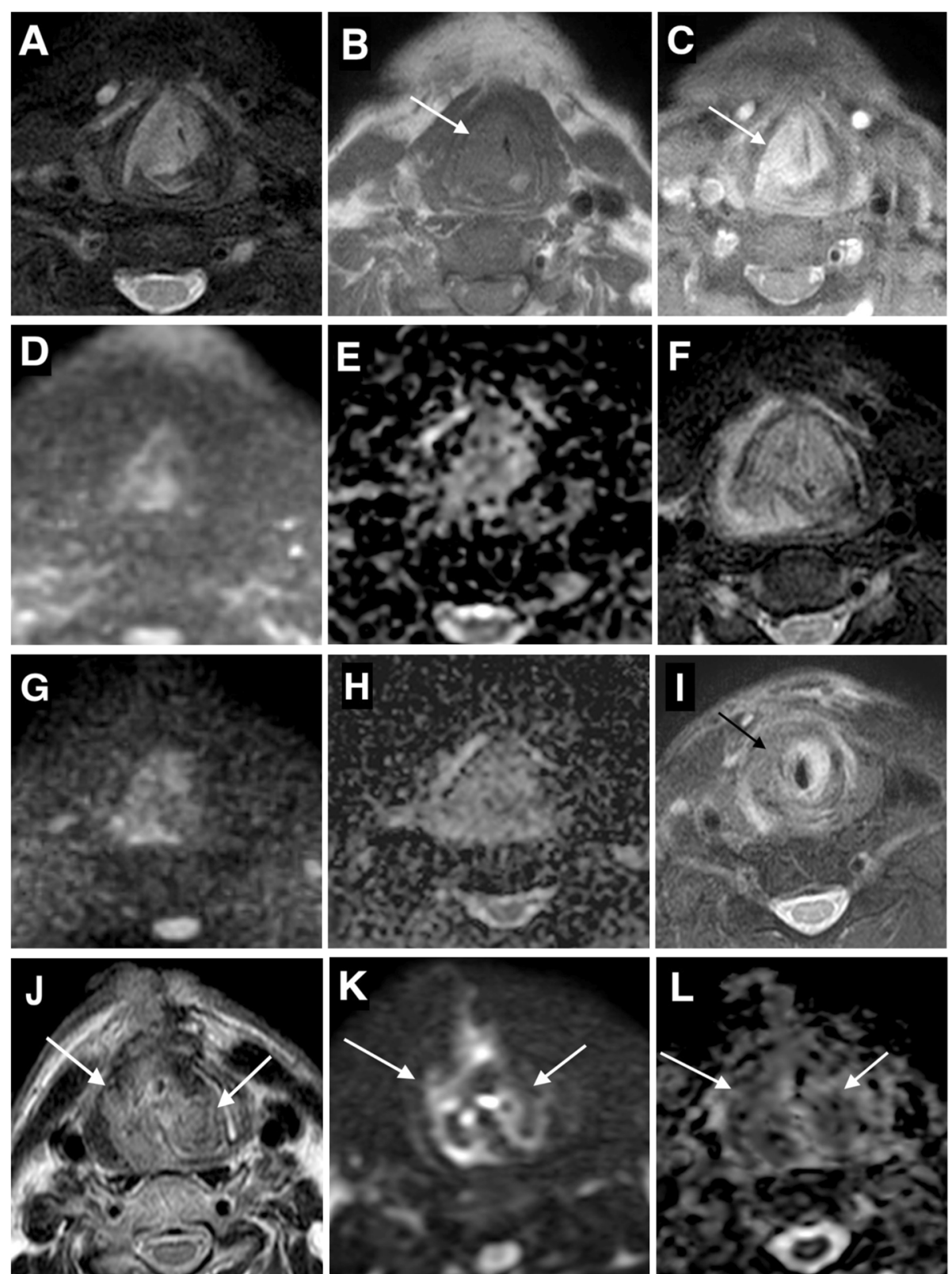

Fig. 5 A 59-year-old male patient with right sided stage IVA transglottic laryngeal SCC (T4aNOMO) treated by concomitant chemoradiotherapy. ae Axial pretreatment MR images. a T2WI with fat suppression, b non-contrast T1WI, c post-GAD T1WI with fat suppression, $\mathbf{d}$ b-1000 TSE-DWI, e the corresponding ADC map, all showed moderately hyperenhancing T2 hyperintense right-sided transglottic soft tissue mass with restricted diffusion ( $\left.A D C=1 \times 10^{-3} \mathrm{~mm}^{2} / \mathrm{s}\right)$. $\mathbf{f}-\mathbf{h}$ Axial midtreatment MR images performed 3 weeks after start of chemoradiotherapy. $\mathbf{f}$ T2WI with fat suppression, $\mathbf{g}$ b-1000 TSE-DWI, $\mathbf{h}$ the ADC map, all showed mild progression in size of the tumor. DWI did not show $A D C$ rise $\left(A D C=1 \times 10^{-3}\right.$ $\mathrm{mm}^{2} / \mathrm{s}$ ). i Axial T2WI 5 weeks after end of CRT revealed suspicious residual tumor (black arrow). $\mathbf{j}$-I Further axial MR images performed 5 months after end of treatment. $\mathbf{j} T 2 \mathrm{Wl}, \mathbf{k}$ high $b$ value DWI, I the corresponding ADC map showed marked progression in size of the residual mass with restricted diffusion $\left(A D C=0.95 \times 10^{-3} \mathrm{~mm}^{2} / \mathrm{s}\right)$, confirming its neoplastic nature and treatment failure

percentage change of mean ADC being significantly higher in local control patient group [5, 15, 23, 24]. King et al. [24] found that the intratreatment ADC fall early or late during treatment had $100 \%$ positive predictive value of locoregional failure; however, ADC rise was found in both groups, but they did not compare between percentage rise in both groups.

The other three studies were done by King et al. [5] Matoba et al. [15], and Vandecaveye et al. [23] who assessed the correlation between locoregional outcome and ADC values as well as tumor volume measurements 

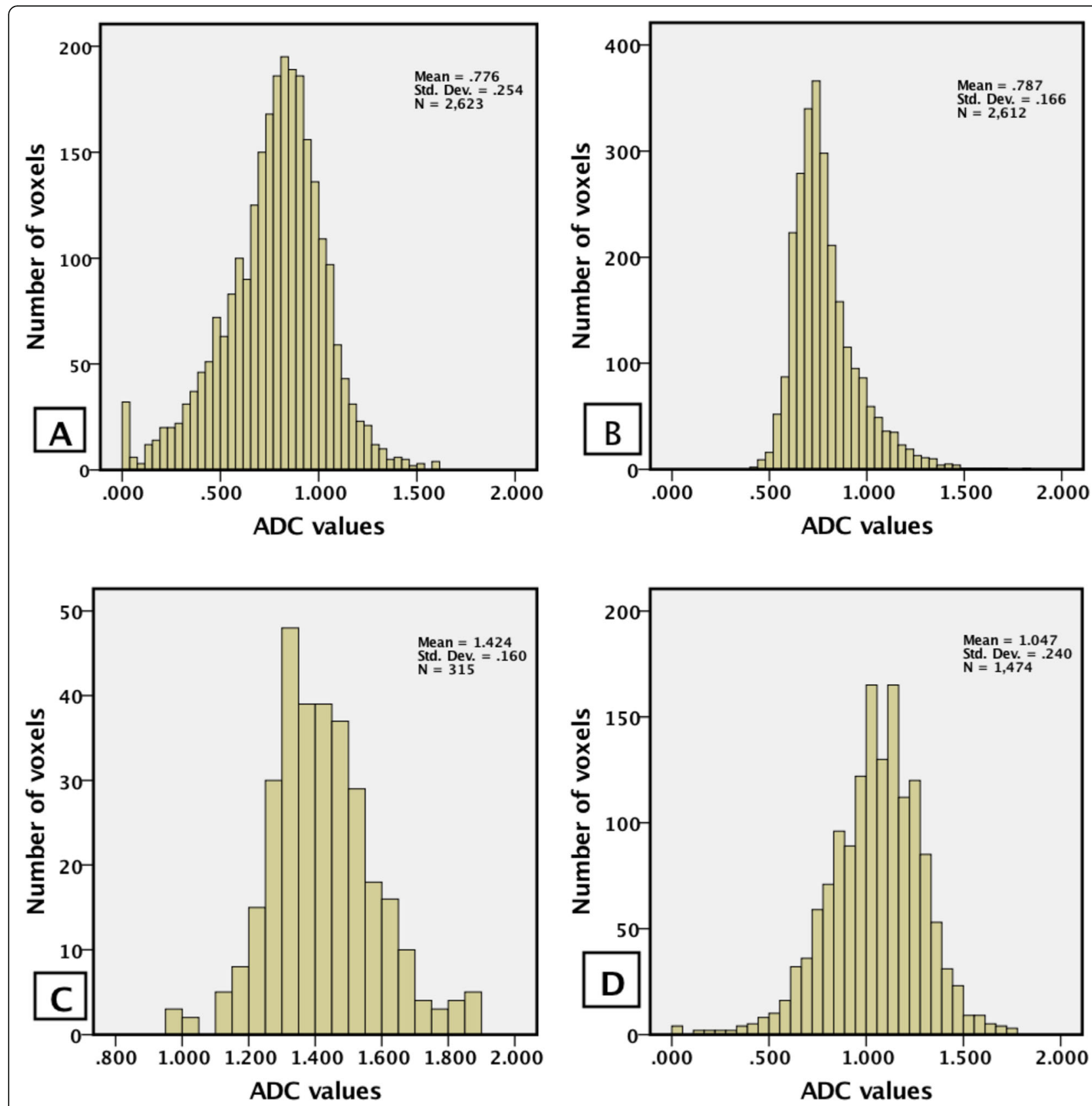

Fig. 6 ADC histograms of the previously demonstrated patients. a, b Histograms of ADC distribution of the primary tumors demonstrated at Figs. 2 and 3, respectively in which local control after CRT was achieved, histograms showed that most of the tumor voxels were of low ADC values. C, d Histograms of ADC distribution of the primary tumors demonstrated at Fig. 4 and 5, respectively in which local failure after CRT was detected, histograms showed that most of the tumor voxels were of high ADC values

in primary tumors and metastatic nodes before and 3 weeks after start of treatment, they found that the intratreatment percentage change of ADC was significant predictor for locoregional control with optimal thresholds of $\geq 15.5 \%, 24 \%$, and $25 \%$ to predict locoregional control after CRT respectively.

A meta-analysis was performed including nine studies assessing the role of DWI (before and early during treatment) in predicting therapeutic response of HNSCC to CRT, they found that DWI had good predictive accuracy (AUC = 0.84) for locoregional failure with the optimum cut-off values for pretreatment ADC ranging from 0.86 to $1.11 \times 10^{-3} \mathrm{~mm}^{2} / \mathrm{s}$ and from 14 to $52.7 \%$ for early intratreatment percentage change in ADC [25].

Another systematic review was done including 11 studies evaluating the value of DWI in prediction of 

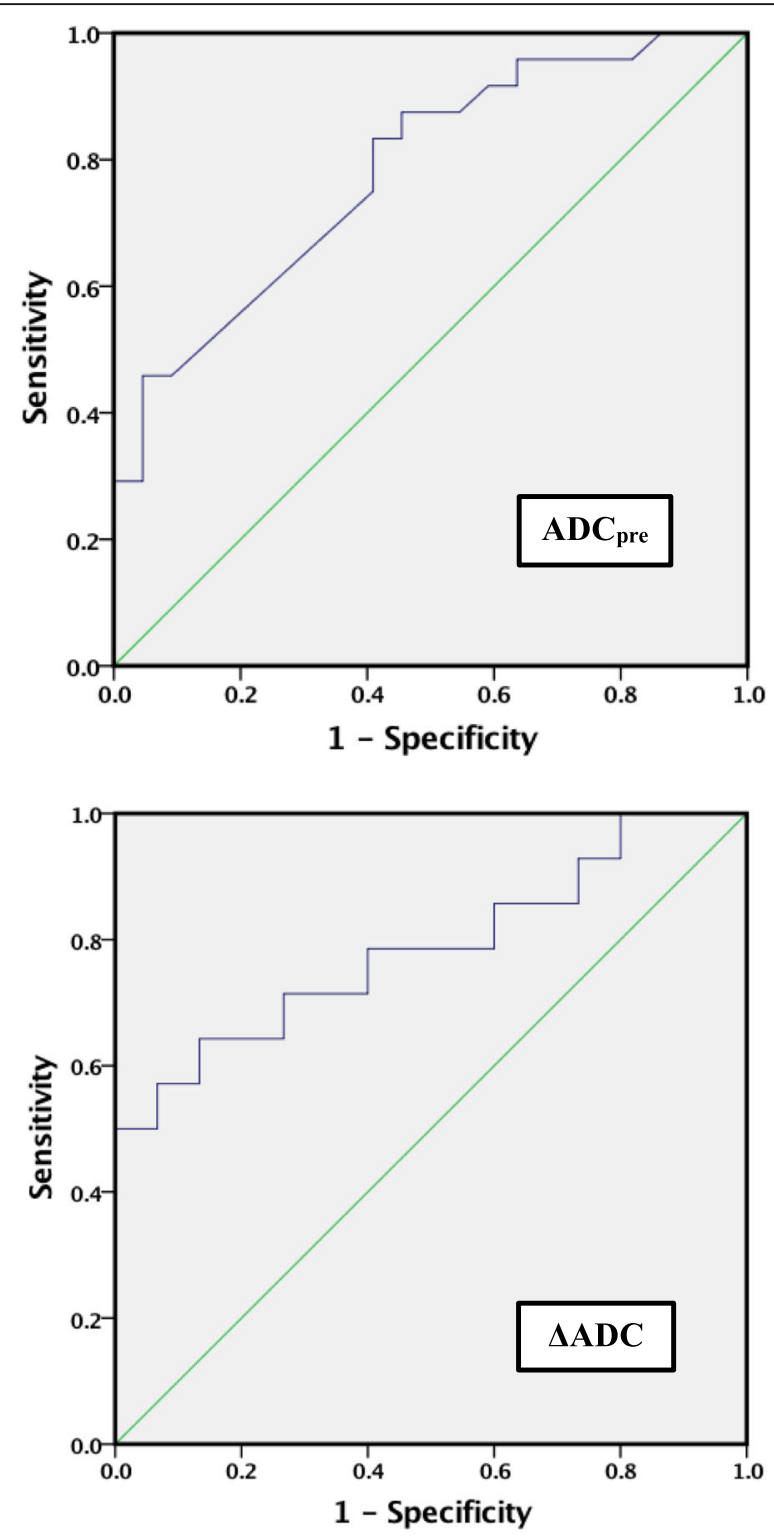

Fig. 7 ROC curve for $A D C_{\text {pre }}$ and $\triangle A D C$ to predict local failure after $C R T$

response of HNSCC to CRT [26]. Five studies found significantly higher pre-treatment ADC values in patients with locoregional failure than in those with locoregional control with cut-off values ranging from 0.86 to $1.2 \times 10^{-3} \mathrm{~mm}^{2} / \mathrm{s}[21,27-30]$. The other 6 studies did not show significant difference in ADC between the two groups [5, 15, 31-34].

Tumor heterogeneity may influence its response to treatment. Tumors with multiple foci of necrosis may exhibit more resistance to treatment. These

Table 4 Agreement (sensitivity, specificity) for ADCpre and $\triangle A D C$ to predict local failure cases

\begin{tabular}{lllllllll}
\hline & AUC & $\boldsymbol{P}$ & $\mathbf{9 5 \%}$ C.I & Cut-off & Sensitivity & Specificity & PPV & NPV \\
\hline ADC $_{\text {pre }}$ & 0.740 & $0.028^{*}$ & $0.559-0.922$ & $>\mathbf{0 . 9 4}$ & 83.33 & 59.09 & 69.0 & 76.5 \\
$\triangle \mathrm{ADC}$ & 0.786 & $0.009^{*}$ & $0.614-0.958$ & $\leq \mathbf{3 3}$ & 71.43 & 60.0 & 62.5 & 69.2 \\
\hline
\end{tabular}

AUC Area under a curve, $P$ value probability value, $C l$ confidence intervals, $N P V$ nssegative predictive value, $P P V$ positive predictive value * Statistically significant at $P \leq 0.05$ 
necrotic foci would measure high ADC values. ADC histogram analysis could be a tool for assessment of tumor heterogeneity in terms of ADC skewness and kurtosis. In this study, no significant difference in pretreatment ADC skewness and kurtosis was found between local control and local failure patient groups. This was compatible with two studies performed by King et al. [5] and Martens et al. [3] who also found no significant difference in pretreatment ADC skewness and kurtosis between local failure and local control groups; however, in the former, they found significant difference in intratreatment ADC skewness and kurtosis between both groups.

This study revealed that tumors with local control has higher percentage of tumor voxels with low ADC values, this was compatible with study performed by Srinivasan et al. [35] who assessed the value of pretreatment mean $\mathrm{ADC}$ and ADC histogram analysis in predicting therapeutic response of HNSCC in correlation with outcome 2 years after treatment, they found that tumors with lower pretreatment mean $\mathrm{ADC}$ and more than $45 \%$ of volume below ADC threshold of $1.15 \times 10^{-3} \mathrm{~mm}^{2} / \mathrm{s}$ may have better outcome.

In this study, pretreatment tumor volume was higher in local failure group yet without statistical significance as with tumor volume changes 2-3 weeks after start of treatment while midtreatment tumor volume was significantly higher in local failure group. These results were compatible with study done by King et al. [5] who found that the intratreatment tumor volume was significantly higher in local failure and was the only predictor that remains significant after multivariate regression analysis.

Diffusion-weighted imaging of the neck is challenging because the neck is a narrow region with complex anatomical structures, multiple tissue-fat, and tissue-air interfaces specifically in our studied areas including all mucosal surfaces, also it is subjected to motion artifacts caused by respiratory movements and unavoidable swallowing movements, as well as metallic artifacts caused by dental prothesis [7]. Also, DWI is highly susceptible to artifacts than other MR imaging sequences, so in this study, non-EPI TSE-based DWI was preferred rather than usual single-shot spin-echo echo-planner DWI used in routine neck imaging to avoid these susceptibility artifacts. TSE-DWI is well established in imaging of cholesteatoma to avoid artifacts of bone-air interface at the skull base [36]. Another study assessed its value in nasopharyngeal imaging differentiating recurrent tumor from post-radiation fibrosis [37]. To the best of our knowledge, limited studies are available in the literature about application of non-EPI TSE-DWI in routine neck imaging. In this study, TSE-DWI was promising giving better imaging quality with less susceptibility artifacts; however, further studies are required to compare its results with single-shot spin-echo echoplanner DWI and to be sure that they give similar ADC measurements.

This study had several limitations such as small number of patients, including SCCs of different sites and stages as well as different treatment strategies, also several factors that are known to affect the biological behavior of SCC such as smoking and HPV status were not assessed in this study. This study was performed on the primary tumors; however, nodal assessment is also important as the nodal status greatly affects the prognosis of HNSCC. The tumor status at 4-12 weeks after the end of treatment was the end point of this study, further studies with long term follow up is required to assess the efficacy of DWI in predicting overall and disease-free survival. Finally, these results still need to be validated in a larger multicenter trial with optimization of sequence parameters, methods of data analysis, and exact timing of assessment to allow for its clinical use.

\section{Conclusions}

Diffusion-weighted MRI could be a potential predictive biomarker for therapeutic response of HNSCC to CRT. Primary tumors with higher pretreatment mean ADC, and a smaller early intratreatment percentage increase of mean ADC would be more likely to fail treatment.

\section{Abbreviations}

HNSCC : Head and neck squamous cell carcinoma; DWl: Diffusion-weighted imaging; CRT: Chemoradiation therapy; ADC: Apparent diffusion coefficient

\section{Acknowledgements}

Our appreciation to Mohamed A.M. Meheissen for his great concern and effort in patient referral and follow-up. We gratefully acknowledge the hard work, efficiency, and devotion of our imaging technicians, which made this work possible.

\section{Authors' contributions}

HMK: design of the study, data collection, CT image interpretation, statistical analysis, and manuscript writing. MMM: CT image interpretation and manuscript editing. ME: design of the study, CT image interpretation, manuscript editing, and sequence alignment. AK: patient referral, manuscript editing, and sequence alignment. SED: design of the study, manuscript editing, and sequence alignment. HMK, MMM, ME, AK, and SED: All authors read and approved the final manuscript.

Funding

No sources of funding.

\section{Availability of data and materials}

The datasets used and/or analyzed during the current study are available from the corresponding author on reasonable request.

\section{Ethics approval and consent to participate}

This study was approved by the Research Ethics Committee of the Faculty of Medicine at Alexandria University in Egypt on 2017 (reference number is 0201048). Written informed consent was obtained from all patients included in this study. 


\section{Consent for publication}

All patients included in this research gave written informed consent to publish the data contained within this study.

\section{Competing interests}

The authors declare that they have no competing interests.

\section{Author details}

'Department of Diagnostic and Interventional Radiology, Faculty of Medicine, Alexandria University, Alexandria, Egypt. ${ }^{2}$ Department of Clinical Oncology and Nuclear Medicine, Faculty of Medicine, Alexandria University, Alexandria, Egypt.

Received: 10 August 2020 Accepted: 21 September 2020

Published online: 06 October 2020

\section{References}

1. Ailianou A, Mundada P, De Perrot T, Pusztaszieri M, Poletti PA, Becker M (2018) MRI with DWI for the detection of posttreatment head and neck squamous cell carcinoma: why morphologic MRI criteria matter. AJNR Am J Neuroradiol 39(4):748-755

2. Vandecaveye V, De Keyzer F, Nuyts S, Deraedt K, Dirix P, Hamaekers P et al (2007) Detection of head and neck squamous cell carcinoma with diffusion weighted mri after (chemo)radiotherapy: Correlation between radiologic and histopathologic findings. Int J Radiat Oncol Biol Phys 67(4):960-971

3. Martens RM, Noij DP, Koopman T, Zwezerijnen B, Heymans M, de Jong MC et al (2019) Predictive value of quantitative diffusion-weighted imaging and 18-F-FDG-PET in head and neck squamous cell carcinoma treated by (chemo)radiotherapy. Eur J Radiol 113:39-50

4. Vandecaveye V, Dirix P, De Keyzer F, de Beeck KO, Vander Poorten V, Roebben I et al (2010) Predictive value of diffusion-weighted magnetic resonance imaging during chemoradiotherapy for head and neck squamous cell carcinoma. Eur Radiol 20(7):1703-1714

5. King AD, Chow KK, Yu KH, Mo FK, Yeung DK, Yuan J et al (2013) Head and neck squamous cell carcinoma: diagnostic performance of diffusionweighted MR imaging for the prediction of treatment response. Radiology 266(2):531-538

6. Chawla S, Kim S, Dougherty L, Wang S, Loevner LA, Quon H et al (2013) Pretreatment diffusion-weighted and dynamic contrast-enhanced MRI for prediction of local treatment response in squamous cell carcinomas of the head and neck. AJR Am J Roentgenol 200(1):35-43

7. Thoeny HC, De Keyzer F, King AD (2012) Diffusion-weighted MR imaging in the head and neck. Radiology 263(1):19-32

8. Vandecaveye V, De Keyzer F, Dirix P, Lambrecht M, Nuyts S, Hermans R (2010) Applications of diffusion-weighted magnetic resonance imaging in head and neck squamous cell carcinoma. Neuroradiology 52(9):773-784

9. Emonts $P$, Bourgeois P, Lemort M, Flamen P (2009) Functional imaging of head and neck cancers. Curr Opin Oncol 21(3):212-217

10. Jansen JFA, Parra C, Lu Y, Shukla-Dave A (2016) Evaluation of head and neck tumors with functional MR imaging. Magn Reson Imaging Clin N Am 24(1):123-133

11. Connolly M, Srinivasan A (2018) Diffusion-weighted imaging in head and neck cancer: technique, limitations, and applications. Magn Reson Imaging Clin N Am 26(1):121-133

12. Padhani AR, Liu G, Koh DM, Chenevert TL, Thoeny HC, Takahara T et al (2009) Diffusion-weighted magnetic resonance imaging as a cancer biomarker: consensus and recommendations. Neoplasia 11(2):102-125

13. El Beltagi AH, Elsotouhy AH, Own AM, Abdelfattah W, Nair K, Vattoth S (2019) Functional magnetic resonance imaging of head and neck cancer: Performance and potential. Neuroradiol J 32(1):36-52

14. Tshering Vogel DW, Zbaeren P, Geretschlaeger A, Vermathen P, De Keyzer F, Thoeny HC (2013) Diffusion-weighted MR imaging including bi-exponential fitting for the detection of recurrent or residual tumour after (chemo)radiotherapy for laryngeal and hypopharyngeal cancers. Eur Radiol 23(2):562-569

15. Matoba M, Tuji H, Shimode Y, Toyoda I, Kuginuki Y, Miwa K et al (2014) Fractional change in apparent diffusion coefficient as an imaging biomarker for predicting treatment response in head and neck cancer treated with chemoradiotherapy. AJNR Am J Neuroradiol 35(2):379-385
16. King AD, Thoeny HC (2016) Functional MRI for the prediction of treatment response in head and neck squamous cell carcinoma: potential and limitations. Cancer Imaging 16(1):23-31

17. de Perrot T, Lenoir V, Domingo Ayllon M, Dulguerov N, Pusztaszeri M, Becker M (2017) Apparent diffusion coefficient histograms of human papillomavirus-positive and human papillomavirus-negative head and neck squamous cell carcinoma: assessment of tumor heterogeneity and comparison with histopathology. AJNR Am J Neuroradiol 38(11):2153-2160

18. Patterson DM, Padhani AR, Collins DJ (2008) Technology insight: water diffusion MRI-a potential new biomarker of response to cancer therapy. Nat CLin Pract Oncol 5(4):220-233

19. Moffat BA, Chenevert TL, Meyer CR, Mckeever PE, Hall DE, Hoff BA et al (2006) The functional diffusion map: an imaging biomarker for the early prediction of cancer treatment outcome. Neoplasia 8(4):259-267

20. Razek A, Khalek AA (2010) Diffusion-weighted magnetic resonance imaging of Head and Neck. Journal of Computer Assisted Tomography 34:808-815

21. Ghany HSA, Samra MFA, El-Saieed M, Gerges AS, Hasan El, Rahman AA et al (2018) Role of DW-MRI and ADC value in monitoring therapy of head and neck squamous cell carcinoma. Egypt J Radiol Nucl Med 49(4):1030-1035

22. Kim S, Loevner L, Quon H, Sherman E, Weinstein G, Kilger A et al (2009) Diffusion-weighted magnetic resonance imaging for predicting and detecting early response to chemoradiation therapy of squamous cell carcinomas of the head and neck. Clin Cancer Res 15(3):986-994

23. Vandecaveye V, Dirix P, De Keyzer F, Op de Beeck K, Vander Poorten V, Hauben E et al (2012) Diffusion-weighted magnetic resonance imaging early after chemoradiotherapy to monitor treatment response in head-andneck squamous cell carcinoma. Int J Radiat Oncol Biol Phys 82(3):1098-1107

24. King AD, Mo FK, Yu KH, Yeung DK, Zhou H, Bhatia KS et al (2010) Squamous cell carcinoma of the head and neck: diffusion-weighted MR imaging for prediction and monitoring of treatment response. Eur Radiol 20(9):2213-2220

25. Zhou Q, Zeng F, Ding Y, Fuller CD, Wang J (2018) Meta-analysis of diffusionweighted imaging for predicting locoregional failure of chemoradiotherapy in patients with head and neck squamous cell carcinoma. Mol Clin Oncol 8(1):197-203

26. Chung SR, Choi YJ, Suh CH, Lee JH, Baek JH (2019) Diffusion-weighted magnetic resonance imaging for predicting response to chemoradiation therapy for head and neck squamous cell carcinoma: a systematic review. Korean J Radiol 20(4):649-661

27. Marzi S, Piludu F, Sanguineti G, Marucci L, Farneti A, Terrenato I et al (2017) The prediction of the treatment response of cervical nodes using intravoxel incoherent motion diffusion-weighted imaging. Eur J Radiol 92:93-102

28. Lombardi M, Cascone T, Guenzi E, Stecco A, Buemi F, Krengli M et al (2017) Predictive value of pre-treatment apparent diffusion coefficient (ADC) in radio-chemiotherapy treated head and neck squamous cell carcinoma. La radiologia medica 122(5):345-352

29. Hatakenaka M, Shioyama Y, Nakamura K, Yabuuchi H, Matsuo Y, Sunami S et al (2011) Apparent diffusion coefficient calculated with relatively high bvalues correlates with local failure of head and neck squamous cell carcinoma treated with radiotherapy. Am J Neuroradiol 32(10):1904-1910

30. Ng S-H, Lin C-Y, Chan S-C, Lin Y-C, Yen T-C, Liao C-T et al (2014) Clinical utility of multimodality imaging with dynamic contrast-enhanced MRI, diffusion-weighted MRI, and 18F-FDG PET/CT for the prediction of neck control in oropharyngeal or hypopharyngeal squamous cell carcinoma treated with chemoradiation. PLoS One 9(12):e115933

31. Wong KH, Panek R, Welsh L, Mcquaid D, Dunlop A, Riddell A et al (2016) The predictive value of early assessment after 1 cycle of induction chemotherapy with 18F-FDG PET/CT and diffusion-weighted MRI for response to radical chemoradiotherapy in head and neck squamous cell carcinoma. J Nucl Med 57(12):1843-1850

32. Schouten CS, de Bree R, van der Putten L, Noij DP, Hoekstra OS, Comans EF et al (2014) Diffusion-weighted EPI-and HASTE-MRI and 18F-FDG-PET-CT early during chemoradiotherapy in advanced head and neck cancer. Quant Imaging Med Surg 4(4):239

33. Paudyal R, Oh JH, Riaz N, Venigalla P, Li J, Hatzoglou V et al (2017) Intravoxe incoherent motion diffusion-weighted MRI during chemoradiation therapy to characterize and monitor treatment response in human papillomavirus head and neck squamous cell carcinoma. J Magn Reson Imaging 45(4): 1013-1023 
34. Galban CJ, Mukherji SK, Chenevert TL, Meyer CR, Hamstra DA, Bland PH et al (2009) A feasibility study of parametric response map analysis of diffusionweighted magnetic resonance imaging scans of head and neck cancer patients for providing early detection of therapeutic efficacy. Transl Oncol 2(3):184-190

35. Srinivasan A, Chenevert TL, Dwamena BA, Eisbruch A, Watcharotone K, Myles JD et al (2012) Utility of pretreatment mean apparent diffusion coefficient and apparent diffusion coefficient histograms in prediction of outcome to chemoradiation in head and neck squamous cell carcinoma. Comput Assist Tomogr 36(1):131-137

36. Dubrulle F, Souillard R, Chechin D, Vaneecloo FM, Desaulty A, Vincent C (2006) Diffusion-weighted MR imaging sequence in the detection of postoperative recurrent cholesteatoma. Radiology 238(2):604-610

37. Huang W, Liu J, Zhang B, Liang L, Luo X, Mei Y et al (2019) Potential value of non-echo-planar diffusion-weighted imaging of the nasopharynx: a primary study for differential diagnosis between recurrent nasopharyngeal carcinoma and post-chemoradiation fibrosis. Acta Radiol 60(10):1265-1272

\section{Publisher's Note}

Springer Nature remains neutral with regard to jurisdictional claims in published maps and institutional affiliations.

\section{Submit your manuscript to a SpringerOpen ${ }^{\circ}$ journal and benefit from:}

- Convenient online submission

- Rigorous peer review

- Open access: articles freely available online

High visibility within the field

- Retaining the copyright to your article

Submit your next manuscript at $\boldsymbol{\nabla}$ springeropen.com 